\title{
Excitatory Synaptic Transmission Between Interneurons and Motoneurons in Chick Spinal Cord Cell Cultures
}

\author{
Richard J. O'Brien' ${ }^{1}$ and Gerald D. Fischbach \\ Department of Anatomy and Neurobiology, Washington University School of Medicine, St. Louis, Missouri 63110
}

\begin{abstract}
We have examined the development of synaptic transmission between interneurons and motoneurons in spinal cord cell cultures. Unitary excitatory synaptic currents and complex bursts of excitatory currents develop rapidly: EPSCs (excitatory postsynaptic currents) were detected in $100 \%$ of the motoneurons by the 4th day after plating. Inhibitory synaptic currents develop more slowly: IPSCs (inhibitory postsynaptic currents) were detected in only $10 \%$ of the motoneurons on day 5 and $40 \%$ on day 8 . During the 1 st and 2 nd days in vitro, $24 \%$ of the motoneurons tested were dye (Lucifer Yellow) coupled to nearby interneurons. The incidence of dye coupling declined during the first week in culture. No coupling was observed between motoneurons.
\end{abstract}

Our data imply that both $G_{1}$ and $G_{2}$ receptors are activated at each synapse. The amplitude of spontaneous excitatory synaptic currents did not change when the motoneuron was hyperpolarized from -50 to $-80 \mathrm{mV}$. This behavior is similar to that of currents induced by glutamate, an agonist that activates 2 types of receptors $\left(G_{1}\right.$ and $\left.G_{2}\right)$ on motoneurons. In addition, a concentration of 2-amino-5-phosphonovaleric acid sufficient to inhibit all $G_{1}$ receptors only partially inhibited the excitatory synaptic currents. Given the conductance of $G_{1}$ and $G_{2}$ channels and the ratio of channels activated during unitary EPSCs, we estimate that as few as $25 G_{1}$ channels and $5 G_{2}$ channels may mediate excitatory interaction between interneurons and motoneurons during the first week in culture.

Neurons dissociated from embryonic chick or mouse spinal cords form excitatory and inhibitory synapses with one another in cell culture (Choi et al., 1981; Fischbach and Dichter, 1974; McDonald et al., 1983; Nelson et al., 1983; Peacock et al., 1973; Ransom et al., 1977). In most previous studies, neurons were examined between 2 and 6 weeks after plating, when they were large enough to be penctrated with conventional intraccllular microelectrodes. Therefore, little is known about the time course of synapse formation in vitro or about the function of newly formed synapses. In addition, the type of spinal cord cell tested was not identified. In chick cultures (O'Brien and Fischbach, 1986a), and probably in mammalian cultures as well, anterior horn motoneurons make up only $1-2 \%$ of the neuronal population. Therefore, most of the PSPs examined to date probably arose at synapses between interneurons.

In this paper we have used Gigaseal, whole-cell recording techniques to assay synaptic interactions among chick neurons

\footnotetext{
Received Jan. 14, 1986; revised Apr. 25, 1986; accepted May 5, 1986.

We are grateful to Dr. Lorna Role for helpful discussions. This work was supported by USPHS Grant NS 18458 (G.D.F.) and by Harvard Medical School Medical Scientist Training Program 'T32 GM07753(R.O.). Correspondence should be addressed to Gerald D. Fischbach, Department of Anatomy and Neurobiology, Washington University School of Medicine, 660 South Euclid Ave., St. Louis, MO 63110.

${ }^{1}$ Present address: Department of Medicine, Massachusetts General Hospital, Fruit Street, Boston, MA 02114.

Copyright (C) 1986 Society for Neuroscience $0270-6474 / 86 / 113284-06 \$ 02.00 / 0$
}

during the first week in culture. We have focused on lateral motor column motoneurons labeled in vivo with Lucifer Yellowwheat germ agglutinin (LY-WGA) conjugates and identified in vitro as previously described (O'Brien and Fischbach, 1986a).

One important issue concerns the type of postsynaptic receptor activated following the release of transmitter from presynaptic interneurons. $N$-Methyl-D-aspartate (NMDA) and nonNMDA receptors - or, as we call them, $G_{1}$ and $G_{2}$ receptorsare present on cultured chick motoneurons ( $\mathrm{O}^{\prime}$ Brien and Fischbach, 1986b), but their distribution in relation to synaptic boutons is not yet known. $G_{1}$ receptors are activated by NMDA and aspartate, and they are blocked by 2-amino-5-phosphonovaleric acid (2-APV) and $\mathrm{Mg}^{2+}$ (reviewed by Watkins and Evans, 1981). The $\mathrm{Mg}^{2+}$ block is voltage dependent, increasing as the membrane is hyperpolarized beyond about $-40 \mathrm{mV}$ (Mayer and Westbrook, 1984; Nowak et al., 1984). Hence, the steadystate $G_{1}$ relation includes a region of negative slope conductance between -40 and $-80 \mathrm{mV} . \mathrm{G}_{2}$ receptors are activated by kainate and quisqualate, and they are not blocked by 2-APV or $\mathrm{Mg}^{2+}$. Hence, the $G_{2}$ current increases more or less linearly as the membrane is hyperpolarized. We have used these criteria to decide whether one or both types of receptors are activated during synaptic transmission.

L-Glutamate is a mixed agonist on chick motoneurons in that it activates both $G_{1}$ and $G_{2}$ receptors (O'Brien and Fischbach, $1986 \mathrm{~b}$ ). Thus, a finding that both types of receptor are activated by synaptic activity would add weight to the already large body of circumstantial evidence implicating L-glutamate as the interneuron-motoneuron excitatory transmitter.

\section{Materials and Methods}

All motoneurons tested in this study were dissociated from embryonic day (E) 6 chick lumbar spinal cords, plated on collagen-coated, myotubecontaining glass coverslips, and grown in Eagle's Minimum Essential Medium containing chick embryo extract $(2 \% \mathrm{vol} / \mathrm{vol})$ and heat-inactivated horse serum $(10 \% \mathrm{vol} / \mathrm{vol})$. Techniques for labeling E5 motoneurons in vivo by retrograde transport of LY-WGA conjugates and for identifying them in heterogeneous spinal cord cultures were described in the first of this series (O'Brien and Fischbach, 1986a).

Patch-clamp, whole-cell recording techniques were also described previously (O'Brien and Fischbach, 1986a, b). When recording synaptic currents, we substituted $\mathrm{K}$-acetate $(140 \mathrm{~mm})$ for $\mathrm{KCl}(140 \mathrm{~mm})$ in the patch electrode solution. The frequency of spontaneously occurring synaptic activity was increased by warming the cultures to $35^{\circ} \mathrm{C}$. Synaptic currents, recorded with a Dagan 8900 amplifier, were bandpass-filtered (Krohn Hite, $0.5 \mathrm{~Hz}-1.2 \mathrm{kHz}$ ) and analyzed online with a PDP 11/23 computer. The baseline was sampled continuously, and once an event exceeded a preset threshold (4-5 pA above the background noise of 1$2 \mathrm{pA}$ ), 1024 points were collected at a rate of $2 \mathrm{kHz}$. We determined the point of maximum inward current and the half-time for current decay. The computer program rejected complex, multiphasic synaptic currents - which probably reflect the coordinated discharge of several interneurons (see Results)-by searching for a positive slope within a fixed interval after a decreasing one. Peak current and current duration were also used to reject bursts of synaptic activity. By choosing proper 
A

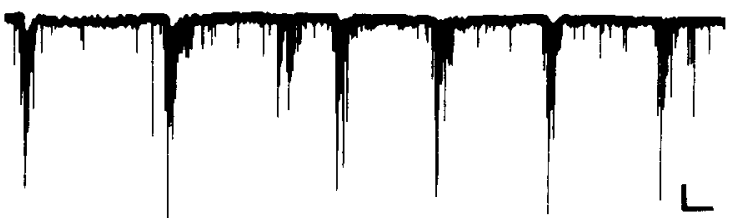

B

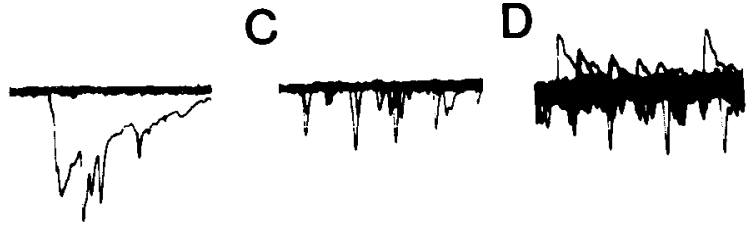

Figure 1. Synaptic currents recorded from motoneurons grown in mixed spinal cord cell cultures. $A$, Rhythmic bursts and unitary synaptic currents recorded at slow sweep speed. Calibration bars, 20 pA, 2 sec. $B$ and $C$. Bursts and unitary events from another motoneuron at faster sweep speed. Calibration bars, $50 \mathrm{pA}$ and $20 \mathrm{msec}$ for $B, 10 \mathrm{pA}$ and 10 msec for $C$. $D$, Membrane potential of a third motoneuron was held at $-30 \mathrm{mV}$, revealing both inward (excitatory) and outward (inhibitory) synaptic currents. Calibration bars, $10 \mathrm{pA}, 10 \mathrm{msec}$.

parameters, we were able to detect more than $95 \%$ of all unitary synaptic potentials and reject all bursts.

Some motoneurons were injected with $\mathrm{LY} \mathrm{CH}\left(4 \%\right.$ in $0.25 \mathrm{M} \mathrm{LiCl}_{2}$ ) with 1 -sec-long hyperpolarizing pulses $(0.25-0.5 \mathrm{nA})$ repeated at a rate of $0.5 \mathrm{~Hz}$. Injection times varied from 5 to $15 \mathrm{~min}$, and the time allowed for dye diffusion varied from $5 \mathrm{~min}$ to $1 \mathrm{hr}$.

\section{Results}

\section{Development of synaptic activity}

Voltage-clamped motoneurons assayed on or after day 2 in vitro displayed 2 types of spontaneous synaptic activity (Fig. 1). The first consisted of rhythmic bursts, each one of which was comprised of large and prolonged inward currents with multiple, superimposed peaks (Fig. 1, $A, B$ ). Such bursts presumably reflect the input of several interneurons discharging in a stereotyped fashion. The second consisted of brief discrete currents on the order of 15 pA (Fig. 1, A, C). Such "unitary" synaptic currents presumably reflect the release of transmitter from a single interneuron. Bursts and unitary currents were eliminated by $10^{-6} \mathrm{M}$ TTX, implying that both are due to action potentialevoked transmitter release.

Unitary synaptic events could be classified as inhibitory or excitatory on the basis of their reversal potentials. When recordings were made with patch electrodes containing $140 \mathrm{~mm}$ $\mathrm{K}$-acetate instead of $\mathrm{KCl}$, some of the currents were reversed in polarity at $-40 \mathrm{mV}$ (Fig. $1 D$ ). Since GABA and glycine currents reverse at about the same potential, this subpopulation of synaptic currents probably reflects transmitter release from inhibitory interneurons (see Choi and Fischbach, 1981). The remaining synaptic currents, which reversed near $0 \mathrm{mV}$ (Fig. 2) presumably reflect input from excitatory interneurons. In 9 cells, the potential at which inverted excitatory currents were first detected was $+5.4 \pm 7.0 \mathrm{mV}$ (mean $\pm \mathrm{SD}$ ). This value must be considered an upper-limit estimate of the true reversal potential because the membrane current noise increased significantly as the cells were depolarized from -50 to $+20 \mathrm{mV}$. Thus, the $10 \mathrm{mV}$ difference between the EPSC reversal potential and the reversal potentials of currents activated by exogenously ap-
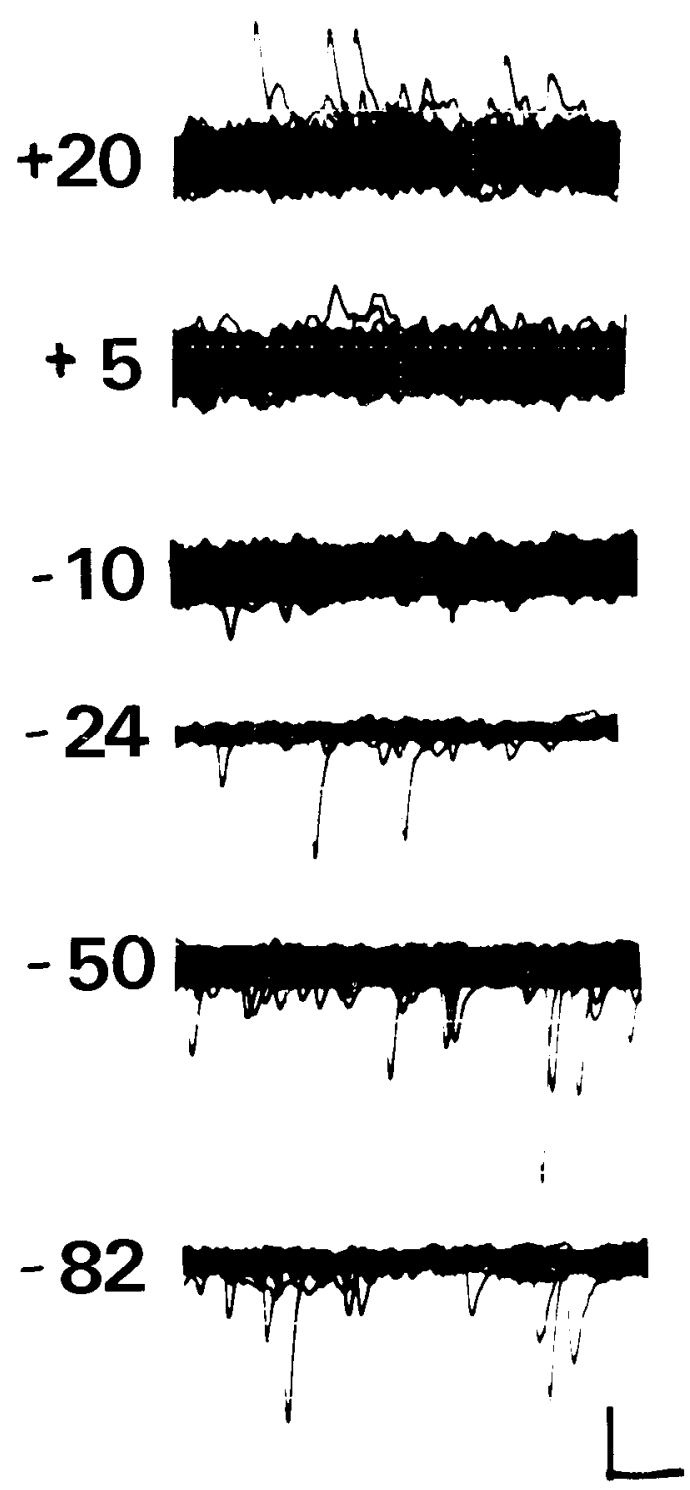

Figure 2. Excitatory synaptic currents recorded at the indicated holding potentials. The extracellular solution contained $2 \mu \mathrm{M}$ strychnine and $200 \mu \mathrm{m}$ bicuculline. Calibration bars, $10 \mathrm{pA}, 10 \mathrm{msec}$.

plied agonists (O'Brien and Fischbach, 1986b) is probably not significant.

The percentage of motoneurons displaying spontaneous excitatory and inhibitory input as a function of time in culture is shown in Figure 3. By the 3rd day after plating, nearly all motoneurons tested exhibited unitary and bursting excitatory input. Inhibitory synaptic currents developed more slowly. Only 5\% of the motoneurons tested on day 5 exhibited IPSCs, and, after $8 \mathrm{~d}$, the incidence was only $40 \%$. Motoneurons could not be identified unambiguously at later times because the fluorescent label was lost with time (O'Brien and Fischbach, 1986a). However, the incidence of IPSCs in unlabeled cells did not reach $100 \%$ until day 14 . The incidence of multiphasic bursts declined as the incidence of inhibitory inputs increased.

Between the 1 st and 2 nd days in culture, 6 of the $25(24 \%)$ of the motoneurons injected with LY were dye coupled to another ncuron (Fig. 4). The incidence of coupling decreased with time in culture, and by $5 \mathrm{~d}$ it was less than $5 \%$. No increase in the incidence of coupling was observed with prolonged injection and diffusion times compared with shorter times. To exclude the possibility of impaling 2 cells at once, dye-coupled cells 


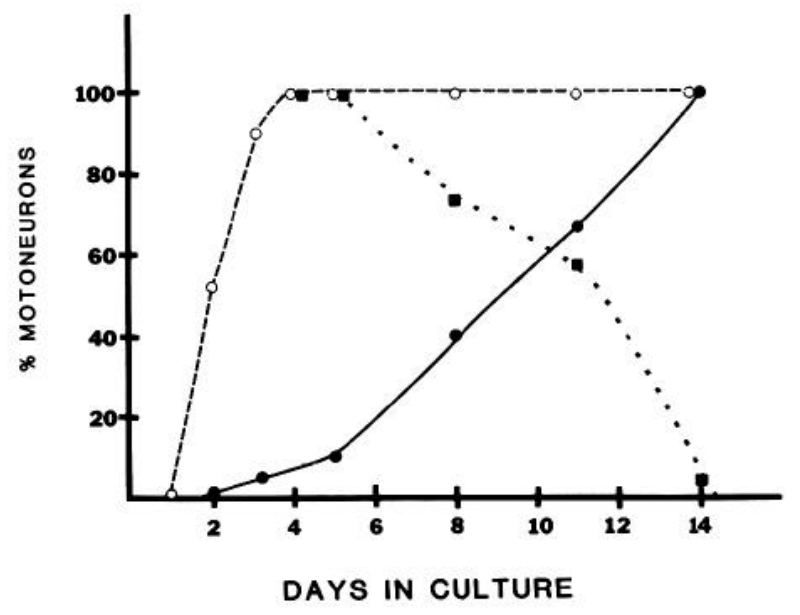

Figure 3. Development of spontaneous synaptic activity. The percentage of motoneurons that exhibited unitary (open circles) or bursting excitatory (closed squares) currents and inhibitory currents (closed circles) is shown as a function of days after plating. Each point represents at least 15 cells from 3 separate platings. Cells studied on days 11 and 14 were not identified as motoneurons (see text).

whose somata were in contact were rejected. Only 3 pairs of 28 tested neurons were in this category.

We never observed dye coupling between 2 moneurons in heterogeneous spinal cord cell cultures, nor did we detect coupling between motoneurons in cultures seeded with sorted cells even when they were plated at high cell density ( 23 pairs tested). It remains to be determined if the specialized junctions that mediate dye coupling represent an early stage of chemical synapse formation.

\section{Involvement of $G_{1}$ and $G_{2}$ receptors in excitatory synaptic transmission}

In this series of experiments we recorded from motoneurons on day 5 or 6 after plating because, at this time, dye coupling (and presumably electrotonic transmission) had declined to a low level, and the incidence of inhibitory input was still negligible. To further ensure that all unitary currents examined were excitatory, recordings were made in the presence of $2 \mu \mathrm{M}$ strychnine and $200 \mu \mathrm{M}$ bicuculline. At these concentrations, the antagonists effectively eliminated the response of motoneurons to saturating concentrations of glycine and GABA, respectively (Choi and Fischbach, 1981).

Evidence for $G_{1}$ and/or $G_{2}$ receptor mediation of synaptic currents was sought by comparing the mean amplitude of spontaneous EPSCs at $-50 \mathrm{mV}$ (resting potential) with the mean at $-80 \mathrm{mV}$. As shown in Table 1, the peak synaptic current mea-

Table 1. Effect of membrane hyperpolarization on synaptic and excitatory amino acid currents

\begin{tabular}{|c|c|c|c|}
\hline \multirow[b]{2}{*}{ Current measured } & \multicolumn{2}{|c|}{ Peak current (pA) } & \multirow{2}{*}{$\begin{array}{l}\text { Change } \\
\text { (\%) }\end{array}$} \\
\hline & $-50 \mathrm{mV}$ & $-80 \mathrm{mV}$ & \\
\hline Synaptic $(n=30)$ & $14.2 \pm 6.61$ & $13.7 \pm 4.9$ & -4 \\
\hline Kainate $\left(10^{-3} \mathrm{M} ; n=10\right)$ & $920 \pm 210$ & $1410 \pm 380$ & +56 \\
\hline Glutamate $\left(10^{-3} \mathbf{M} ; n=10\right)$ & $300 \pm 70$ & $320 \pm 59$ & +5 \\
\hline NMDA $\left(10^{-3} \mathrm{M} ; n=10\right)$ & $130 \pm 25$ & $15 \pm 10$ & -87 \\
\hline
\end{tabular}

Effect of membrane hyperpolarization on the magnitude of synaptic and excitatory amino acid currents. Unitary excitatory synaptic currents were recorded from 30 identified motoneurons at -50 and at $-80 \mathrm{mV}$. Responses of 10 other motoneurons in the same cultures to kainate, glutamate, and NMDA at $10^{-3} \mathrm{M}$ were also determined. Each entry represents the mean \pm SD.

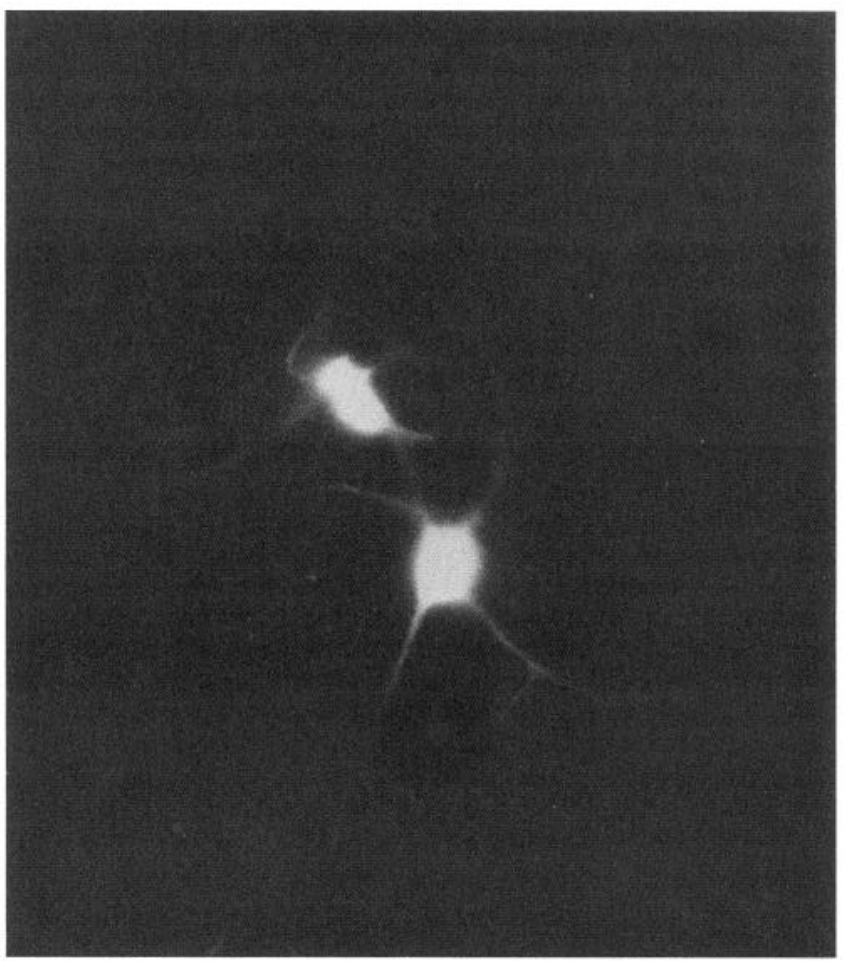

Figure 4. Dye coupling between a motoneuron (lower cell) and an interneuron (upper cell) examined $24 \mathrm{hr}$ after plating. The motoneuron was identified by its content of fluorescent granules (LY-WGA) prior to injection of $\mathrm{LY} \mathrm{CH}$.

sured in 30 motoneurons did not change. In contrast, the current activated by kainate, a selective $\mathrm{G}_{2}$ agonist, increased by $55 \%$, while that activated by the $G_{1}$ agonist NMDA decreased by $90 \%$. The error associated with these measurements is small because hyperpolarization from -50 to $-80 \mathrm{mV}$ required only $50-100 \mathrm{pA}$ of current and resulted in an increase in peak-topeak membrane current noise of only 1-2 pA. The failure of EPSCs to increase or decrease in size with increases in membrane potential is reminiscent of currents induced by L-glutamate, and it suggests that both $G_{1}$ and $G_{2}$ receptors are activated by synaptically released transmitters.

In addition to estimating the mean EPSC, we examined the distribution of synaptic current amplitudes at resting membrane potential and at $-80 \mathrm{mV}$. Figure $5 A$ shows histograms of synaptic currents recorded from a motoneuron at -50 and -80 $\mathrm{mV}$. Figure $5 B$ is a composite of EPSCs from 10 other motoneurons. The distributions are similar at both levels of membrane potential. The $\chi^{2}$ analyses of the histograms from the single cell and from the sample of 10 revealed no significant differences between -50 and $-80 \mathrm{mV}(p>0.5 ; 7$ and $16 \mathrm{df}$, respectively). Linear-regression analysis of paired bins showed that the data could be fit with a correlation coefficient of 0.96 .

To explore further the possibility that EPSCs involve activation of $G_{1}$ and $G_{2}$ receptors, we recorded in the presence and absence of $1 \mathrm{~mm} 2$-APV, a specific $\mathrm{G}_{1}$ receptor antagonist (Evans et al., 1982; see O'Brien and Fischbach, 1986b). If $\mathrm{G}_{1}$ receptors are involved in synaptic transmission, inhibition of synaptic currents by $2-\mathrm{APV}$ should occur at resting potential (ca. -50 $\mathrm{mV}$ ), where $\mathrm{G}_{1}$ receptors are active, but not at $-80 \mathrm{mV}$, where they are not (O'Brien and Fischbach, 1986b). The antagonist was applied with pressure pulses $0.5 \mathrm{sec}$ long repeated every 5 sec. As shown in Table 2 and Figure 6, 2-APV decreased the mean peak synaptic current at resting potential by $30 \%$ but had no effect at $-80 \mathrm{mV}$. Most EPSCs, recorded at $-50 \mathrm{mV}$ in the 


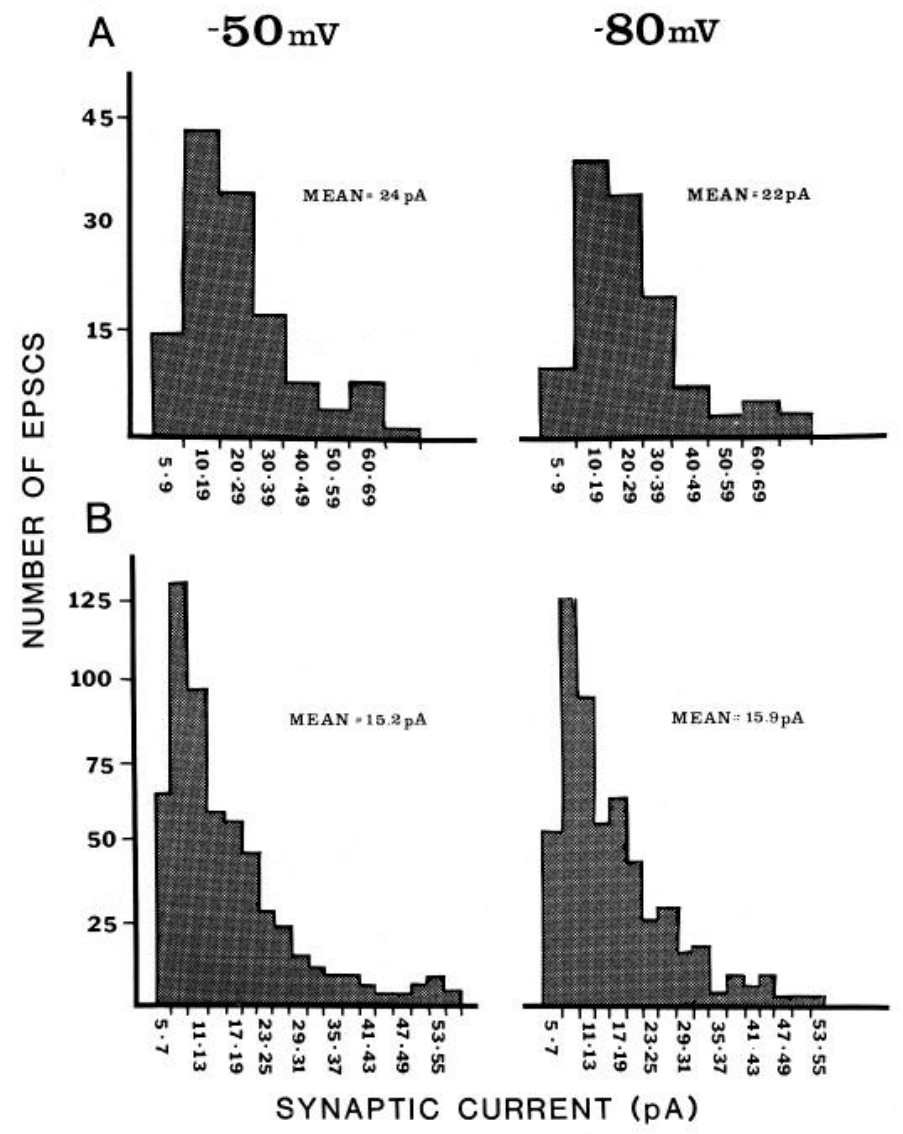

Figure 5. EPSC amplitude histograms recorded at -50 and $-80 \mathrm{mV}$. $A$, Unitary EPSCs recorded from 1 motoneuron $(n=135$ at $-50 \mathrm{mV}$; $n=142$ at $-80 \mathrm{mV}$ ). $B$, Unitary EPSCs from 10 motoneurons were pooled $(n=541$ at $-50 \mathrm{mV} ; n=562$ at $-80 \mathrm{mV})$. The mean EPSCs of the 10 neurons ranged from 13.1 to $17.2 \mathrm{pA}$. Bicuculline and strychnine were present in the bath.

presence of 2-APV, were less than $10 \mathrm{pA}$ (the first bin; Fig. 6), so it is possible that the smallest potentials were lost in the baseline noise. Thus, the degree of inhibition by 2-APV may be even greater than $30 \%$. Although the involvement of $\mathrm{G}_{1}$ receptors in synaptic transmission may be underestimated, it is clear that many unitary excitatory synaptic currents remain in the presence of a saturating concentration of 2-APV. Thus, $G_{2}$ receptors must also be involved. As expected for $G_{2}$ currents, the amplitude of EPSCs detected in the presence of 2-APV increased with increases in membrane potential (Table 2), and they were blocked by $10 \mathrm{~mm}$ gamma-D-glutamylglycine $(\gamma \mathrm{GG}$; data not shown).

The lack of effect of 2-APV at $-80 \mathrm{mV}$ serves as a control for nonspecific effects of this antagonist on the postsynaptic membrane or on presynaptic nerve terminals. Because 2-APV was applied by pressure ejection, it presumably diffused over a relatively wide area and thus might alter the activity of neurons that provide synaptic input to the target motoneuron. We assume that this is a random process, affecting terminals that release large amounts of transmitter and terminals that release small amounts equally. The lack of effect of 2-APV on the distribution of synaptic currents at $-80 \mathrm{mV}$ ensures that this is the case.

\section{Discussion}

Motoneurons dissociated from the lumbar spinal cord of $6 \mathrm{~d}$ chick embryos receive input from excitatory interneurons within 1-2 d after plating. The formation of inhibitory synapses occurs

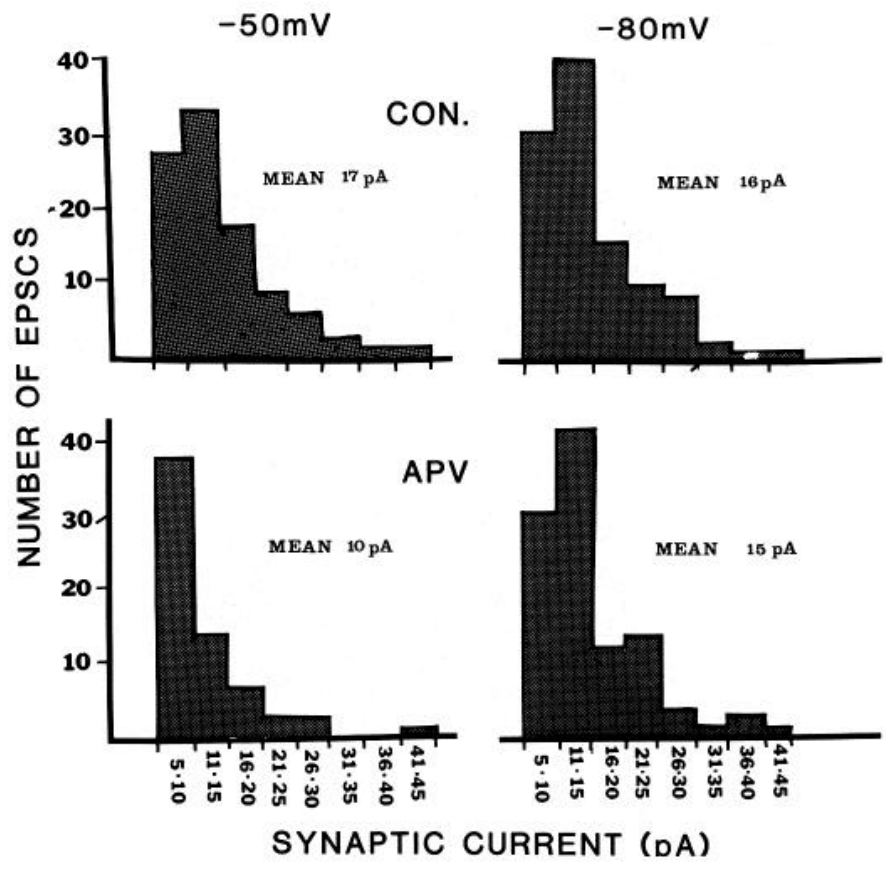

Figure 6. EPSC amplitude histograms recorded at -50 and $-80 \mathrm{mV}$ in the presence and absence of 2-APV. The antagonist was applied at a concentration of $1 \mathrm{~mm}$ by pressure ejection. Bicuculline and strychine were present in the bath.

on a slower time scale; few neurons exhibited IPSCs until the second week in culture. Both results are expected from electronmicroscopic, behavioral, and electrophysiological studies of intact embryos. Axodendritic synapses have been found in the marginal zone of the chick lumbar cord as early as E4 (Oppenheim and Foelix, 1972; Oppenheim et al., 1976), and local spinal cord circuits become functional at about the same time (Bekoff, in press; Hamburger, 1963). On the other hand, segmental, strychnine-sensitive inhibition is not prominent until after E10 (Oppenheim, 1975). Thus, our observations indicate that the progress of synapse formation in vivo is mimicked, at least on a qualitative level, in cell cultures. Jackson et al. (1982) also found that the appearance of inhibitory interactions was delayed relative to excitatory interactions in mouse spinal cord cell cultures.

The effects of 2-APV, a competitive $\mathrm{G}_{1}$ receptor antagonist, and of membrane hyperpolarization on spontaneously occurring EPSCs imply that both $\mathrm{G}_{1}$ and $\mathrm{G}_{2}$ receptors are activated during excitatory transmission between embryonic chick interneurons and motoneurons in vitro. The mean EPSC was reduced by at least $30 \%$ in the presence of $1 \mathrm{~mm} 2-\mathrm{APV}$, a concentration that blocks all motoneuron $G_{1}$ receptors (O'Brien and Fischbach, 1986b). Because 2-APV-resistant synaptic currents increased with hyperpolarization and were reduced in size by $\gamma \mathrm{GG}$, we

Table 2. Inhibition of synaptic currents by 2 -APV

\begin{tabular}{llcc}
$\begin{array}{l}\text { Holding potential } \\
(\mathrm{mV})\end{array}$ & \multicolumn{2}{l}{ Peak current $(\mathrm{pA})$} & $\begin{array}{l}\text { Change } \\
(\%)\end{array}$ \\
\cline { 2 - 3 } & Control & 2-APV, 1 mM & \\
\hline$-50(n=14)$ & $14.1 \pm 5.3$ & $9.8 \pm 3.9$ & 30 \\
$-80(n=17)$ & $15.6 \pm 5.7$ & $15.1 \pm 6.4$ & 3
\end{tabular}

Unitary excitatory synaptic currents recorded from identified motoneurons in the presence and absence of $1 \mathrm{~mm} 2$-APV (applied by pressure ejection). Ten of the motoneurons were analyzed at both -50 and $-80 \mathrm{mV}$. Each entry represents the mean $\pm \mathrm{SD}$ 
assume that $70 \%$ of the synaptic currents flow through $G_{2}$ channels.

We examined a population of synapses rather than individual synaptic boutons, so the effect of 2-APV and hyperpolarization might be interpreted in 1 of 2 ways. First, both receptors might be present at each synapse. Alternatively, some synapses might contain only $G_{1}$ receptors and others only $G_{2}$ receptors. According to the segregated receptor hypothesis, the effect of 2 -APV implies that $30 \%$ of the synapses activate $G_{1}$ receptors and $70 \%$ of the synapses activate $G_{2}$ receptors. If the voltage dependencc of synaptic currents is the samc as that of currents induced by applied agonists, then the following argument makes this hypothesis unlikely. When the membrane potential is shifted from -50 to $-80 \mathrm{mV}, 30 \%$ of the EPSCs should decrease by $90 \%$, and the remaining $70 \%$ should increase by $55 \%$. The shape of the EPSC amplitude histogram should change depending on the relative amplitudes of $G_{1}$ and $G_{2}$ EPSCs at $-50 \mathrm{mV}$. If the mean amplitudes are similar at $-50 \mathrm{mV}$ or if $\mathrm{G}_{2}$ EPSCs were larger than $\mathrm{G}_{1}$ EPSCs at $-50 \mathrm{mV}$, then the amplitude distribution would be broader at $-80 \mathrm{mV}$. If $\mathrm{G}_{1}$ EPSCs are larger than $\mathrm{G}_{2}$ EPSCs at $-50 \mathrm{mV}$, the histogram at $-80 \mathrm{mV}$ would be more peaked. The predicted change is not small: The number of events observed near the mean at $-50 \mathrm{mV}$ should decrease (or increase) by $66 \%$ when the membrane is polarized to -80 $\mathrm{mV}$. It is striking, therefore, that the shape of the EPSC histogram did not change as the membrane was hyperpolarized. According to the $\chi^{2}$ distribution, the probability that the 2 histograms shown in Figure 6 differ by $60 \%$ is less than 0.01 . Linearregression analysis implies that only $7 \%$ of the currents sampled at $-80 \mathrm{mV}$ cannot be accounted for by the variation observed at $-50 \mathrm{mV}$. Therefore, we conclude that the segregated receptor hypothesis can be rejected and that both types of receptor are present at each excitatory synapse.

Recordings from ventral roots of isolated, hemisected rat and frog spinal cords have emphasized the role of $G_{1}$ (NMDA) receptors at interneuron-motoneuron synapses. Stimulation of dorsal roots evokes a complex, graded depolarization of the segmental ventral root, the early phase of which is thought to reflect monosynaptic activation of motoneurons by $I_{A}$ afferents. The late phase of the depolarization is thought to be due to polysynaptic activation of motoneurons by interneurons (Otsuka and Konishi, 1974). 2-APV depresses the late depolarization by more than $90 \%$ (Evans et al., 1982). In addition, the ability of mono- and diamino dicarboxylic acids to block dorsal root evoked responses is correlated with their ability to block responses evoked by NMDA (Evans et al., 1979). At this time, we cannot decide if the differences between these results and our finding that $G_{1}$ receptors contribute only $30 \%$ of the interneuron-induced current are due to differences between species, stage of development, or methodology. It is particulary difficult to compare electrotonic potentials recorded several millimeters away from the cell body that last more than $1000 \mathrm{msec}$ with soma currents that rise and fall in less than $5 \mathrm{msec}$.

Paired intracellular recordings from Xenopus motoneurons and interneurons have shown that a single interneuron can activate both $G_{1}$ and $G_{2}$ receptors (Dale and Roberts, 1985). The unitary EPSP was complex, with a relatively slow $(10-\mathrm{msec}-$ rise), APV-sensitive component $\left(G_{1}\right)$ superimposed on a fast, APV-insensitive component $\left(G_{2}\right)$. During repetitive stimulation, the 2 components "failed" independently of each other. While quantal responses may have gone undetected, this result raises the possibility that in Xenopus motoneurons $G_{1}$ and $G_{2}$ receptors are segregated beneath different synaptic boutons. No cvidence for $G_{1}$ receptor activation was obtained in a recent study of cultured mouse spinal cord neurons (Nelson et al., 1986). EPSPs or EPSCs recorded under voltage clamp increased linearly with membrane hyperpolarization, and they were unaffected by $1 \mathrm{~mm}$ 2-APV. Motoneurons were not identified, so the synapses examined in the mouse cultures may be of a different class than the ones examined in this study. In any case, the issue of species differences must be raised again, and, since the mouse neurons were tested after 4-6 weeks in culture, the stage of development must be considered as well.

$\mathrm{G}_{2}$ receptors apparently predominate at $\mathrm{I}_{A}-$ motoneuron synapses in the spinal cord. The early depolarization of frog and rat ventral roots following dorsal root stimulation is not blocked significantly by 2-APV (Evans et al., 1982), and $\mathrm{I}_{\mathrm{A}}$ EPSPs that arise near the somata of cat motoneurons increase linearly with increase in soma membrane potential (Finkel and Redman, 1983). $G_{2}$ receptors may play a major role in the hippocampus as well. EPSPs evoked in granule cells of the dentate gyrus following stimulation of the perforant pathway are blocked by $\gamma$ GG but not by 2 -APV (Crunelli et al., 1983). Synaptically generated field potentials by Schaffer collaterals are not blocked by 2-APV (Collingridge et al., 1983). In addition, EPSPs recorded in cultures of rat hippocampal pyramidal neurons (Rothman and Samaie, 1985) are not blocked significantly by 2 -APV, and they increase in size with increases in membrane potential.

Our finding that both $\mathrm{G}_{1}$ and $\mathrm{G}_{2}$ receptors contribute to EPSCs recorded in embryonic chick motoneurons during the first week in culture strongly suggests that L-glutamate is the excitatory interneuron-motoneuron transmitter at this time, in this species. Of the 5 amino acid receptor agonists tested ( $\mathrm{O}^{\prime} B$ rien and Fischbach, 1985b), L-glutamate was the only mixed agonist capable of activating motoneuron $G_{1}$ and $G_{2}$ receptors. Aspartate activates only $G_{1}$ receptors even at saturating concentrations, so it can be ruled out as the sole synaptic mediator in this system. For the same reason, $\mathrm{G}_{2}$-selective agonists similar to kainate and quisqualate cannot be considered transmitter candidates. Of course, more complex explanations might be offered, such as the release of more than 1 mediator or the release of an as yet unidentified "glutamate-like" compound.

The small size of unitary synaptic currents, $15 \mathrm{pA}$ on average, is remarkable. Since chick motoneuron $G_{1}$ and $G_{2}$ channel conductances are 26 and $10 \mathrm{pS}$, respectively, as few as $5 \mathrm{G}_{1}$ and 20 $\mathrm{G}_{2}$ channels may be activated following the discharge of an interneuron. No comparable data are available for more mature interneuron-motoneuron synapses, but in the adult cat spinal cord the single $\mathrm{I}_{\mathrm{A}}$ afferents studied by Finkel and Redman (1983) generated 330 pA EPSCs. Nelson et al. (1983) studied synapses between mouse spinal cord neurons maintained in culture for 4-6 weeks that were probably more mature than the synapses in our 6-d-old cultures. Based on their values of input resistance (ignoring input capacitance) and unitary EPSP amplitude, we calculate that the underlying synaptic currents were at least 1500 pA.

Presynaptic factors such as a relatively small number of synaptic boutons or low level of transmitter release per bouton may account for the small unitary synaptic currents during the first week in culture. In addition, the density of receptors in the postsynaptic membrane may be low. As noted previously (O'Brien and Fischbach, 1986b), the extrasynaptic receptor density on motoneurons may be quite low during the first week in culture. The peak inward current evoked by saturating concentrations of glutamate was only about $400 \mathrm{pA}$. It is possible that synapses form on regions of membrane that are no different from adjacent extrasynaptic areas in regard to receptor density. The fact that the proportion of $G_{1}$ and $G_{2}$ currents activated by synaptically released transmitter (30 and $70 \%$, respectively) is similar to the proportion of $G_{1}$ and $G_{2}$ currents activated following pressure ejection of L-glutamate over the entire soma and proximal dendrites, 38 and $62 \%$, respectively (O'Brien and Fischbach, 1986b), is consistent with this suggestion. These arguments are not entirely conclusive, however. The ratio of receptors may be independent of receptor density. The small number of active channels may reflect a low probability of channel 
opcning (O'Bricn and Fischbach, 1986b) rather than low receptor density. Thus, the possibility that receptors are clustered at the newly formed synapses examined in this study has not been ruled out. Indeed, we have found regions of high glutamate sensitivity ("hot spots") by focal iontophoresis of the amino acid (O'Brien and Fischbach, 1986c). It remains to be determined if the hot spots are located at glutaminergic synaptic boutons.

\section{References}

Bekoff, $\Lambda$. (in press) Ontogeny of chicken motor behaviors: Evidence for multi-use limb pattern generating circuitry. In Proceedings of the Symposium on Neurobiology of Vertebrate Locomotion.

Choi, D. W., and G. D. Fischbach (1981) GABA conductance of chick spinal cord and dorsal root ganglion neurons in cell culture. J. Neurophysiol. 45: 605-620.

Choi, D. W., D. H. Forb, and G. D. Fischbach (1981) GABA-mediated synaptic potentials in chick spinal cord and sensory neurons. J. Neurophysiol. 45: 632-643.

Collingridge, G. L., S. J. Kehl, and H. McLennan (1983) The antagonism of amino acid induced excitation of rat hippocampal CA1 neurons in vitro. J. Physiol. (Lond.) 334: 19-31.

Crunelli, V., S. Forda, and J. S. Kelly (1983) Blockade of amino acid induced depolarizations and inhibition of excitatory post synaptic potentials in rat dentate gyrus. J. Physiol. (Lond.) 341: 627-640.

Dale, N., and A. Roberts (1985) Dual component amino-acid-mediated synaptic potentials: Excitatory drive for swimming in Xenopus embryos. J. Physiol. (Lond.) 363: 35-59.

Evans, R. H., A. A. Francis, K. Hunt, D. J. Oakes, and J. C. Watkins (1979) Antagonism of excitatory amino acid-induced responses and of synaptic excitation in the isolated spinal cord of the frog. $\mathrm{Br}$. J. Pharmacol. 67: 591-603.

Evans, R. H., A. A. Francis, A. W. Jones, D. A. S. Smith, and J. C. Watkins (1982) The effects of a series of $w$-phosphonic, $\alpha$-carboxylic amino acids on electrically evoked and excitant amino acid induced responses in isolated spinal cord preparations. $\mathrm{Br}$. J. Pharmacol. 75: 65-75.

Finkel, A. S., and S. J. Redman (1983) The synaptic current evoked in cat spinal motoneurons by impulses in single group $1 \mathrm{a}$ axons. $J$. Physiol. (Lond.) 342: 615-632.

Fischbach, G. D., and M. A. Dichter (1974) Electrophysiological and morphologic properties of neurons in dissociated chick spinal cord cell cultures. Dev. Biol. 37: 100-116.

Hamburger, V. (1963) Observations and experiments on spontaneous rhythmical behavior in the chick. Dev. Biol. 7: 533-545.

Jackson, M. B., H. Lecar, D. E. Brenneman, S. Fitzgerald, and P. G. Nelson (1982) Electrical development in spinal cord cell cultures. J. Neurosci. 2: 1052-1061.
Mayer, M. L., and G. L. Westbrook (1984) Mixed agonist action of excitatory amino acids on mouse spinal cord neurons under voltage clamp. J. Physiol. (Lond.) 354: 29-53.

McDonald, R. L., R. Y. K. Pun, E. A. Neale, and P. G. Nelson (1983) Synaptic interactions between mammalian central neurons in cell culture. I. Reversal potential for excitatory postsynaptic potentials. J. Neurophysiol. 49: 1428-1441.

Nelson, P. G., K. C. Marshall, R. Y. K. Pun, C. N. Christian, W. H. Sheriff, R. L. McDonald, and F. E. Neale (1983) Synaptic interactions between mammalian central neurons in cell culture. II. Quantal analysis of EPSP's. J. Neurophysiol. 49: 1442-1458.

Nelson, P. G., R. Y. K. Pun, and G. L. Westbrook (1986) Synaptic excitation in cultures of mouse spinal cord enurons: Receptor pharmacology and behavior of synaptic currents. J. Physiol. (Lond.) 372. 169-182.

Nowak, L., P. Bregestovski, P. Ascher, A. Herbert, and A. Prochiantz (1984) Magnesium gates glutamate-activated channels in mouse central neurons. Nature 307: 462-465.

O'Brien, R. J., and G. D. Fischbach (1986a) Isolation of embryonic chick motoneurons and their survival in vitro. J. Neurosci. 6: 32653274.

O'Brien, R. J., and G. D. Fischbach (1986b) Excitatory synaptic transmission between interneurons and motoneurons in chick spinal cord cell cultures. J. Neurosci. 6: 3284-3289.

O'Brien, R. J., and G. D. Fischbach (1986c) Modulation of embryonic chick motoneuron glutamate sensitivity by interneurons and agonists. J. Neurosci. 6: 3290-3296.

Oppenheim, R. W. (1975) The role of supraspinal input in embryonic motility: A rccxamination in the chick. J. Comp. Neurol. 160: 3750 .

Oppenheim, R. W., and R. F. Foelix (1972) Synaptogenesis in the chick embryo spinal cord. Nature 235: 126-128.

Oppenheim, R. W., I. Chu-Wang, and R. F. Foelix (1976) Some aspects of synaptogenesis in the spinal cord of the chick embryo: A quantitative electron microscopic study. J. Comp. Neurol. 161:383418.

Otsuka, M., and S. Konishi (1974) Electrophysiology of mammalian spinal cord in vitro. Nature 252: 733-744.

Peacock, J. H., P. G. Nelson, and M. W. Goldstone (1973) Electrophysiologic study of neurons dissociated from spinal cords and dorsal root ganglia of fetal mice. Dev. Biol. 30: 137-152.

Ransom, B. R., P. N. Bullick, and P. G. Nelson (1977) Mouse spinal cord in cell culture. III. Neuronal chemosensitivity and its relationship to synaptic activity. J. Neurophysiol. 40: 1163-1177.

Rothman, S. M., and M. Samaie (1985) Electrophysiology and morphology of the developing hippocampus of fetal rats. J. Neurophysiol. 54: 699-711.

Watkins, J. C., and R. H. Evans (1981) Excitatory amino acid transmitters. Annu. Rev. Pharmacol. Toxicol. 21: 165-204. 